\title{
Modeling and Dynamic Analysis of Spherical Roller Bearing with Localized Defects: Analytical Formulation to Calculate Defect Depth and Stiffness
}

\author{
Behnam Ghalamchi, Jussi Sopanen, and Aki Mikkola \\ Department of Mechanical Engineering, Lappeenranta University of Technology, P.O. Box 20, 53851 Lappeenranta, Finland \\ Correspondence should be addressed to Behnam Ghalamchi; behnam.ghalamchi@lut.fi
}

Received 15 April 2015; Accepted 30 September 2015

Academic Editor: Vadim V. Silberschmidt

Copyright (C) 2016 Behnam Ghalamchi et al. This is an open access article distributed under the Creative Commons Attribution License, which permits unrestricted use, distribution, and reproduction in any medium, provided the original work is properly cited.

\begin{abstract}
Since spherical roller bearings can carry high load in both axial and radial direction, they are increasingly used in industrial machineries and it is becoming important to understand the dynamic behavior of SRBs, especially when they are affected by internal imperfections. This paper introduces a dynamic model for an SRB that includes an inner and outer race surface defect. The proposed model shows the behavior of the bearing as a function of defect location and size. The new dynamic model describes the contact forces between bearing rolling elements and race surfaces as nonlinear Hertzian contact deformations, taking radial clearance into account. Two defect cases were simulated: an elliptical surface on the inner and outer races. In elliptical surface concavity, it is assumed that roller-to-race-surface contact is continuous as each roller passes over the defect. Contact stiffness in the defect area varies as a function of the defect contact geometry. Compared to measurement data, the results obtained using the simulation are highly accurate.
\end{abstract}

\section{Introduction}

Bearings have an essential effect in dynamic behavior of rotating machinery and a simple dynamic model is important for analysis purposes. Predicting any type of bearing fault might protect the whole system from further failure and damage. Defects cause early fatigue in bearings. In practice, bearing imperfections are categorized in two major groups, distributed defects (i.e., waviness) and local defects (i.e., spalls on the raceways) $[1,2]$.

A large amount of literature has been published dealing with mathematical models for bearing local defect diagnosis. One of the early researches in bearing with defects was conducted by McFadden and Smith [3, 4]. Vibration model shows impulses equal to rolling element passing frequency caused by the interaction of rolling elements and defects. Tandon and Choudhury [1] could detect characteristic frequencies when the defect is located on the roller.

Nakhaeinejad and Bryant [5] introduced a multibody dynamic model to study vibration response in rolling element bearings with a local fault. They compared the effects of defect type and size with various radial loads in dynamic behavior of the bearing. Wang et al. [6] used a multibody dynamic approach for simulation of cylindrical roller bearing with local faults. Contact forces are calculated by combining Hertzian contact theory and the slice method. Local defects deflections are defined by the time-varying excitation. Vibration simulation of ball bearings for both local and distributed imperfections is introduced by Sopanen and Mikkola $[7,8]$. Local defects were categorized by length and height of defects.

Kiral and Karagülle [9] applied finite element method in vibration analysis of rolling bearing. They could detect multiple defects on bearing components using frequency and time factors. They proposed the loading mechanism to generate the nodal excitation which can be used in finite element method. Rafsanjani et al. [10] studied the nonlinear model of roller bearing with local defects. Equations of motion were linearized using the modified Newmark time integration technique. Stability of the bearing with local defects was explored using the classical Floquet theory. 
Kankar et al. [11] used response surface technique to diagnose local faults in high speed rolling element bearings. Discrete spectrum shows peaks at the characteristic frequencies of the bearing. They could also predict accurate spectrum amplitude height compared to experimental results. Tadina and Boltežar [12] developed the dynamic analysis of a faulty roller bearing during run-up. This model considered the effect of centrifugal force. Defect is located on the inner and outer raceways and defined as part of ellipsoidal depression and it causes contact stiffness variation in the defect region. Liu et al. [13] combined Hertzian contact theory with the piecewise function to evaluate the vibration behavior of a roller bearing with the local defect. Kankar et al. [14] analyzed the small-size local defect's effects on the dynamic behavior of ball bearings. Behzad et al. [15] introduced a new model to estimate the vibration which originates from faulty roller bearings. They showed that when a defect grows in the bearing, stochastic excitation becomes stronger in the defective area. Sawalhi and Randall $[16,17]$ studied the vibration of combined gear bearing system with localized bearing faults. They used the same diagnostic techniques for simulated and experimental data and could observe similar behavior for both. Vibration response of spalled rolling element bearings is also demonstrated by Sawalhi and Randall [18]. They found that acceleration response for entry into a spall-like fault is different from the response for exit. Niu et al. [19] proposed the model for a local defect at high speed ball bearings. They showed that, for a high speed rolling bearing, both high speed effects and influences of defects should be considered. In this study defect properties (size and type) have not been taken into account.

Recently, the authors of [21] compared the vibration signals of a faulty bearing at different operational speeds. They studied the effect of the path of roller in the defect region for developing an algorithm to estimate the size of the defect. Petersen and Howard [22] studied a faulty bearing where defect zone is larger than the angular distance between rollers. Results illustrated the effect of defect size on rigid body modes of system which is originated from bearing stiffness variations. Unbalanced rotor-coaxial water pump with a local defect is studied in [23]. The local defect is modeled as periodic excitations which are caused by unbalance force. Liu et al. [24] proposed a new model to find out the effect of defect size on vibration characteristics of system caused by timevarying contact stiffness which is not taken into account in earlier studies.

One of the first studies on measurement techniques for bearing health monitoring was done by Tandon and Choudhury [25]. Defect detection methods are continuously developed and several more studies have been published [2632].

A wide range of studies has been conducted to study defects in ball bearings. However, they are limited in case of spherical roller bearings. Cao and Xiao [33] introduced a vibration analysis of spherical roller bearing. Considering the effect of local imperfections on the dynamic behavior of the bearing is promising in this paper. This model is suffering from low computational efficiency which results from the system's high number of degrees of freedom.

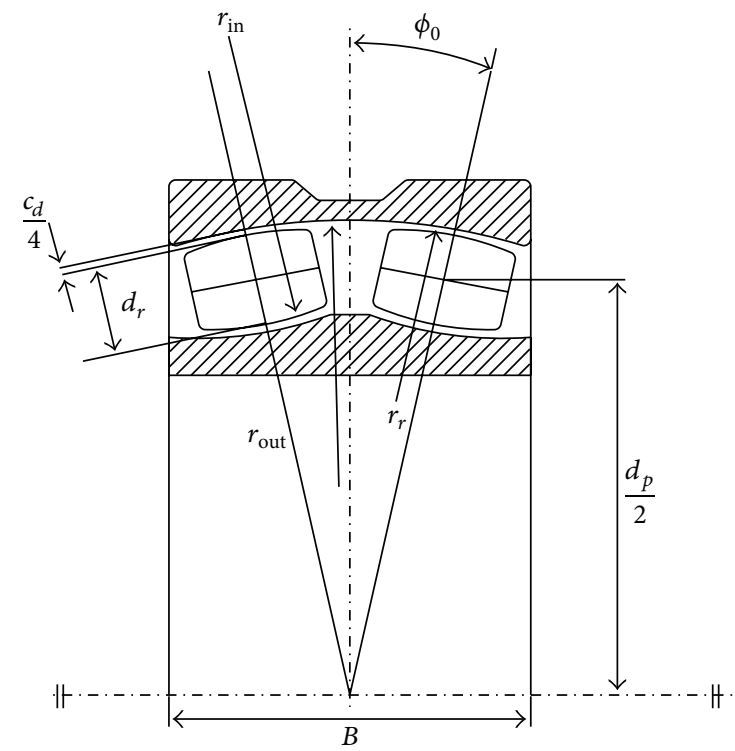

FIGURE 1: Geometric parameters of spherical roller bearing [20].

Recently, the authors of [34] studied the effects of offsized rollers on behavior of spherical roller bearings. They found that error in roller diameter might change the force acting on each roller.

This paper introduces the vibration analysis of the spherical roller bearing with local imperfections in the inner and outer raceways. Nonlinear Hertzian contact theory is used to describe the rollers' force in contact with inner and outer raceways. Radial clearance is another nonlinear term which has been considered in calculation. It is assumed that the defect located on the inner and outer rings has an elliptical cross section. With this assumption, roller-to-race-surface contact is continuous as each bearing roller passes over the defect. Variation of radii of curvature in the contact area in defect region causes the different contact stiffness. Numerical examples consider the effect of the elliptical defect's size and location on dynamic behavior of rotor-bearing system. The introduced mathematical model is verified by measurement data.

\section{Modeling of the Spherical Roller Bearing}

A modeling approach for the basic spherical roller bearing model is presented earlier in [20,35]. For the completeness of this paper, this model is briefly reviewed in this section. In this case, to reduce the computational complexity of the system, some simplifications are used in the model. It is assumed that no slipping occurs during bearing operation. Since in typical operating conditions of SRBs the centrifugal forces that arise from rollers are significantly smaller than the bearing contact force, the centrifugal forces are neglected in this study. It is also defined that inner ring is connected to the rotor rigidly. Also bearing damping has not been taken into account in this study. Figure 1 [20] shows important parameters of spherical roller bearing.

In this model, summations of individual roller contact forces lead to the bearing load calculation [35]. When 

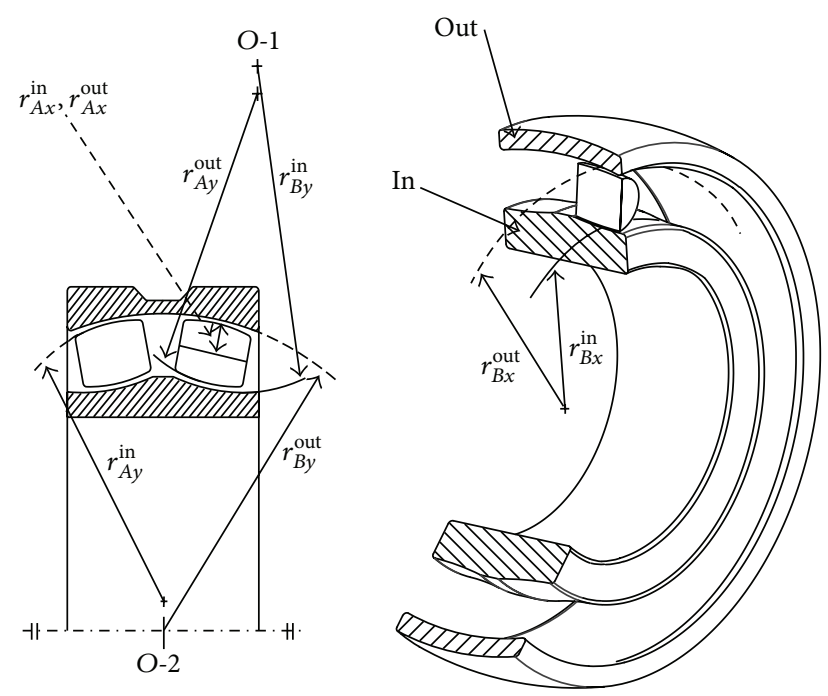

FIGURE 2: Radii of curvature for spherical roller bearing components [20].

spherical roller bearings are loaded moderately, the roller's contact surface can be considered elliptical [36]. Therefore, the $i$ th roller contact force in row $j$ can be calculated as [35]

$$
F_{j}^{i}=k_{\text {con }}^{\text {tot }}\left(\delta_{\beta_{j}^{i}}\right)^{3 / 2}
$$

where $k_{\text {con }}^{\text {tot }}$ is the contact stiffness coefficient of roller in contact with inner and outer race and $\delta_{\beta_{j}^{i}}$ is the rollers' and the races' elastic deformation, which is is determined from relative displacements among the inner and outer raceways. The initial distance, between centers of two raceways $(O-1, O-$ $2)$, is [35]

$$
A_{0}=\left|r_{B y}^{\text {out }}\right|+\left|r_{B y}^{\text {in }}\right|-d_{r}-\frac{c_{d}}{2}
$$

where $r_{B y}^{\text {out }}$ and $r_{B y}^{\text {in }}$ are the radii of curvature for the inner and outer raceways as shown in Figure 2 [20]. $d_{r}$ and $c_{d}$ are roller diameter and bearing internal clearance, respectively.

The equivalent loaded distance can be formulated as

$$
A\left(\beta_{j}^{i}\right)=\sqrt{\left(\delta_{z j}^{i}\right)^{2}+\left(\delta_{r j}^{i}\right)^{2}}
$$

where $\delta_{z j}^{i}$ and $\delta_{r j}^{i}$ are roller axial and radial displacements:

$$
\begin{aligned}
& \delta_{z j}^{i}=A_{0} \sin \left(\phi_{0}\right)+e_{z}, \\
& \delta_{r j}^{i}=A_{0} \cos \left(\phi_{0}\right)+e_{x} \cos \left(\beta_{j}^{i}\right)+e_{y} \sin \left(\beta_{j}^{i}\right),
\end{aligned}
$$

where $e_{x}, e_{y}$, and $e_{z}$ are displacements in the global coordinate and $\beta_{j}^{i}$ is the roller's angular position (see Figure 3). Contact direction is negative in the 1st row and positive in the 2 nd row of rollers.

Displacement among inner and outer races is given by

$$
d\left(\beta_{j}^{i}\right)=\left|r_{B y}^{\text {out }}\right|+\left|r_{B y}^{\text {in }}\right|-A\left(\beta_{j}^{i}\right) .
$$

Elastic compression becomes

$$
\delta_{\beta_{j}^{i}}=d_{r}-d\left(\beta_{j}^{i}\right) .
$$

And the contact direction for each roller can be calculated as

$$
\phi_{j}^{i}=\tan ^{-1}\left(\frac{\delta_{z j}^{i}}{\delta_{r j}^{i}}\right) .
$$

Lastly, the bearing force in the global coordinate can be calculated as

$$
\begin{aligned}
& F_{x}^{b}=-\sum_{j=1}^{2} \sum_{i=1}^{N} F_{j}^{i} \cos \phi_{j}^{i} \cos \beta_{j}^{i}, \\
& F_{y}^{b}=-\sum_{j=1}^{2} \sum_{i=1}^{N} F_{j}^{i} \cos \phi_{j}^{i} \sin \beta_{j}^{i}, \\
& F_{z}^{b}=-\sum_{j=1}^{2} \sum_{i=1}^{N} F_{j}^{i} \sin \phi_{j}^{i},
\end{aligned}
$$

where $N$ is the number of rollers in one row. It should be noted that only negative values in the rollers contact force are not taken into account $\left(F_{j}^{i}=0\right)$.

\section{Local Defects Mathematical Modeling}

In general, imperfections are the main vibration source in the roller bearing. This paper studied the vibration response that occurs from local imperfections on the inner and outer raceways of spherical roller bearing. In most of the earlier studies of local defects in roller bearings, it was assumed that the rollers lose their connections in the district of the defect, and it is modeled with a large impulsive force on rotor bearing systems [1]. Recently, Tadina and Boltežar [12] have proposed the model of the defect on raceways as an ellipsoidal shape and it leads to change in contact stiffness in the defect district. This study uses the same approach for modeling defects in spherical roller bearings.

3.1. Defect on Outer Race. Figure 4 shows the elliptical defect on outer race. Midpoint of the defect is positioned at $\phi$. The angular width of the defect is $\phi_{D}$ and the maximum depth is $D_{d}$. When a roller goes over the defect, the elastic deformation in defect district can be written as

$$
\delta\left(\beta_{j}^{i}\right)_{D}=d_{r}-d\left(\beta_{j}^{i}\right)-\delta^{+}\left(\beta_{j}^{i}\right) .
$$

In $(6), \delta^{+}\left(\beta_{j}^{i}\right)$ is the extra displacement in the defect region, which should be withdrawn from general displacement (see Appendix A) in comparison with (9). This additional displacement is defined only when the roller passes a defect district, $\phi-\phi_{D} / 2<\beta_{j}^{i}<\phi+\phi_{D} / 2$.

Variation in radii of curvature in the defect region leads to different contact stiffness. Consequently, new contact stiffness can be calculated according to Hertzian contact theory [35]. Nevertheless, the calculation of new stiffness 


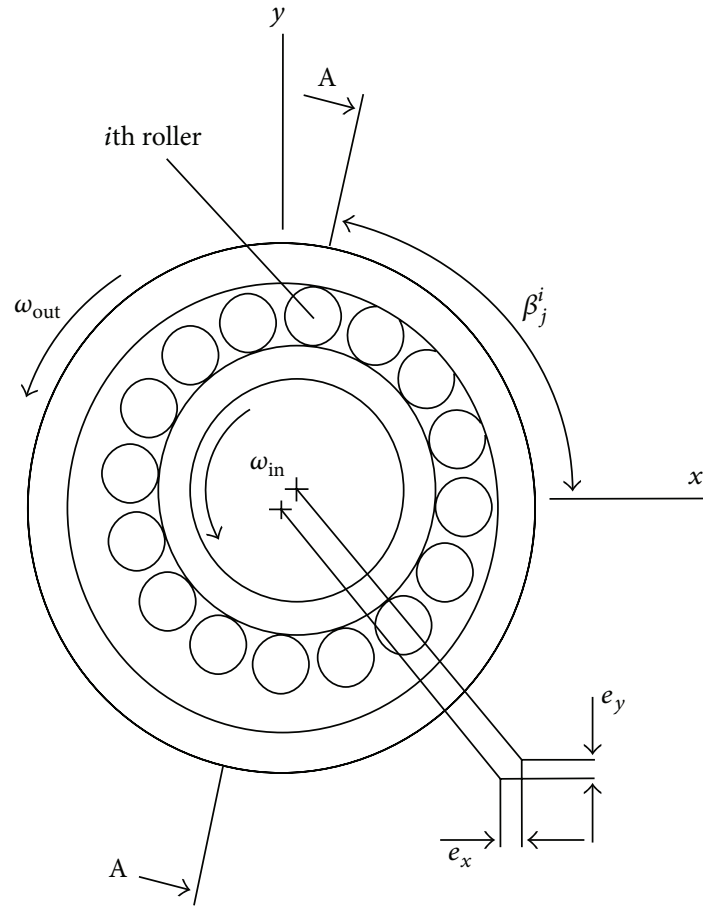

(a)

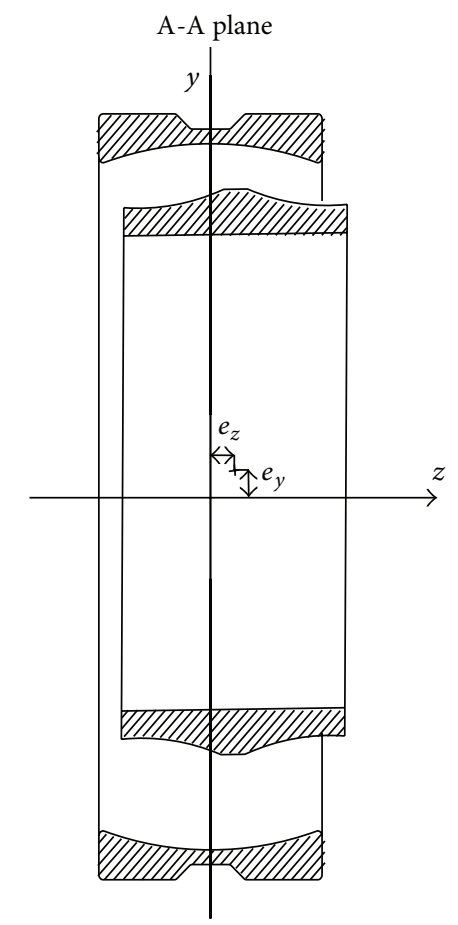

(b)

FIGURE 3: Displacements in the global $x y z$-coordinate [20].

follows the original routines; only the radii of curvature $r_{B x}^{\text {out }}$ (2) have to be recalculated as shown in [12]

$$
r_{B x}^{\text {out }}=\frac{m_{e} n_{e}}{\left(m_{e}^{2} \sin ^{2} \tau+n_{e}^{2} \cos ^{2} \tau\right)^{3 / 2}},
$$

where $m_{e}$ and $n_{e}$ are ellipse principal axes and $\tau$ is a polar constant, calculated as

$$
\tau=\tan ^{-1}\left(\frac{m_{e}}{n_{e}} \tan \phi\right) .
$$

From (1) and (9) finally the roller contact force in defect district can be expressed as follows:

$$
F_{j, D}^{i}=k_{\mathrm{con}, D}^{\mathrm{tot}}\left(\delta\left(\beta_{j}^{i}\right)_{, D}\right)^{3 / 2} \cos \left(\beta_{j}^{i}-\theta_{\text {con }}\right),
$$

where $D$ indicates the defect region, $k_{\text {con, } D}^{\text {tot }}$ is the contact stiffness, and $\theta_{\text {con }}$ is contact angle of roller in defect region (Figure 4).

3.2. Defect on Inner Race. Corresponding to the outer race defect, for an inner race defect (Figure 5), the elastic deformation at defect region will be evaluated as

$$
\delta\left(\beta_{j}^{i}\right)_{, D}=\delta^{+}\left(\beta_{j}^{i}\right)-d_{r}+d\left(\beta_{j}^{i}\right)
$$

and the roller contact force can be expressed as follows:

$$
F_{j, D}^{i}=k_{\text {con }, D}^{\mathrm{tot}}\left(\delta\left(\beta_{j}^{i}\right)_{, D}\right)^{3 / 2} \cos \left(\theta_{\text {con }}-\beta_{j}^{i}\right),
$$

where $k_{\text {con }, D}^{\text {tot }}$ is the contact stiffness which follows the same calculation routine as in (10) and (11).
TABLE 1: Geometric parameters and material properties of bearing, 22216-EK

\begin{tabular}{lccc}
\hline Free contact angle & $\phi_{0}$ & 8.25 & deg. \\
Roller diameter & $d_{r}$ & 15.544 & $\mathrm{~mm}$ \\
Inner race radius & $r_{\text {in }}$ & 63.2 & $\mathrm{~mm}$ \\
Outer race radius & $r_{\text {out }}$ & 63.2 & $\mathrm{~mm}$ \\
$\begin{array}{l}\text { Roller contour } \\
\text { radius }\end{array}$ & $r_{r}$ & 61.49 & $\mathrm{~mm}$ \\
Bearing width & $B$ & 33 & $\mathrm{~mm}$ \\
Clearance & $c_{d}$ & 41 & $\mu \mathrm{m}$ \\
$\begin{array}{l}\text { Bearing pitch } \\
\text { diameter }\end{array}$ & $d_{p}$ & 132 & $\mathrm{~mm}$ \\
$\begin{array}{l}\text { Number of rows } \\
\text { Number of rollers }\end{array}$ & $n_{z}$ & 2 & - \\
in each row & $N$ & 21 & - \\
$\begin{array}{l}\text { Modulus of } \\
\text { elasticity }\end{array}$ & $E$ & 206 & $\mathrm{Gpa}$ \\
Poisson's ratio & $v$ & 0.3 & - \\
\hline
\end{tabular}

\section{Numerical Results}

In this part, numerical examples are presented for a single spherical roller bearing with local defect. The studied SRB is the 22216-EK and Table 1 shows the geometric parameters and material properties of the bearing, whereas the dimensions are depicted explicitly in Figure 1. In these sets of examples, effect of defect size is considered.

4.1. Load Analysis for Bearing with Outer Ring Defects. This model is implemented to study the vibration response of 


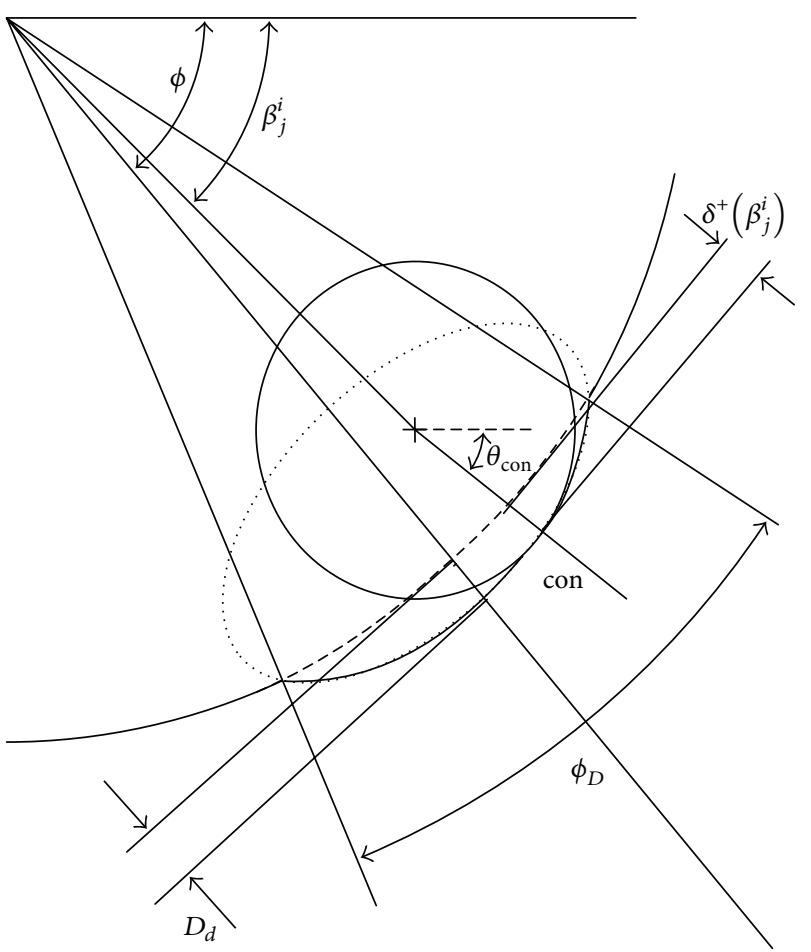

FIGURE 4: Defect on outer race [20].

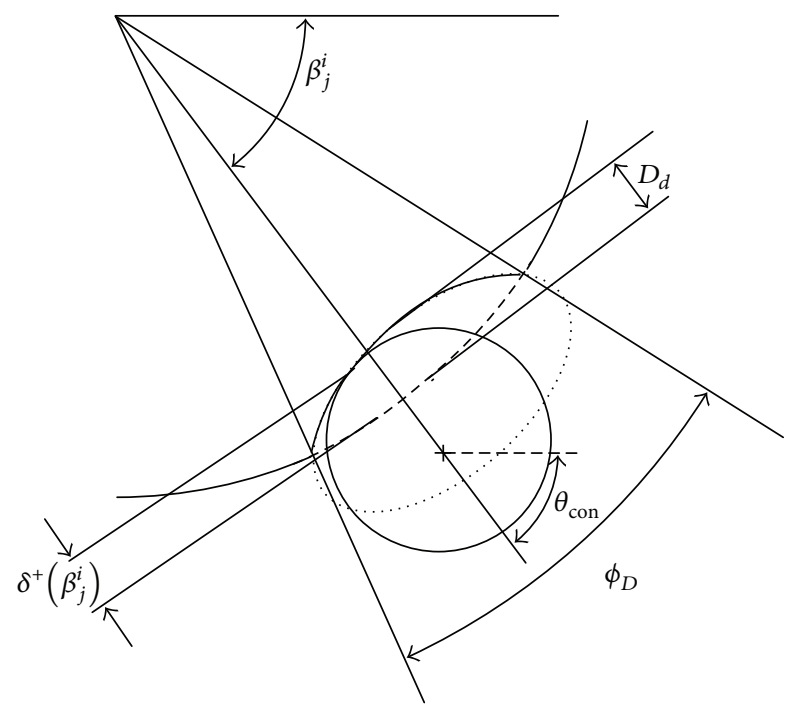

Figure 5: Defect on inner race [20].

the bearing with outer race defect. Figure 6 shows the defect which is located on one side of the outer race. The defect parameters are presented in Table 2 and it is located in 280 degrees from the $x$-axis and maximum depth of the defect is $0.05 \mathrm{~mm}$. Initial displacement for center of bearing in the vertical direction is assumed to be equal to $e_{y}=-0.0324 \mathrm{~mm}$ and inner race rotates with rate of $\omega_{\text {in }}=78.54 \mathrm{rad} / \mathrm{s}(750 \mathrm{rpm})$. Calculation routine for characteristics frequencies of SRB is introduced in Appendix B, and results for $750 \mathrm{rpm}$ are listed in Table 6.
TABLE 2: Outer ring defects parameters.

\begin{tabular}{lccc}
\hline Defect & Major axis $a$ & Minor axis $b$ & Defect width \\
\hline I & $10 \mathrm{~mm}$ & $5 \mathrm{~mm}$ & $1.60 \mathrm{~mm}$ \\
II & $20 \mathrm{~mm}$ & $10 \mathrm{~mm}$ & $2.77 \mathrm{~mm}$ \\
III & $30 \mathrm{~mm}$ & $15 \mathrm{~mm}$ & $5.04 \mathrm{~mm}$ \\
\hline
\end{tabular}

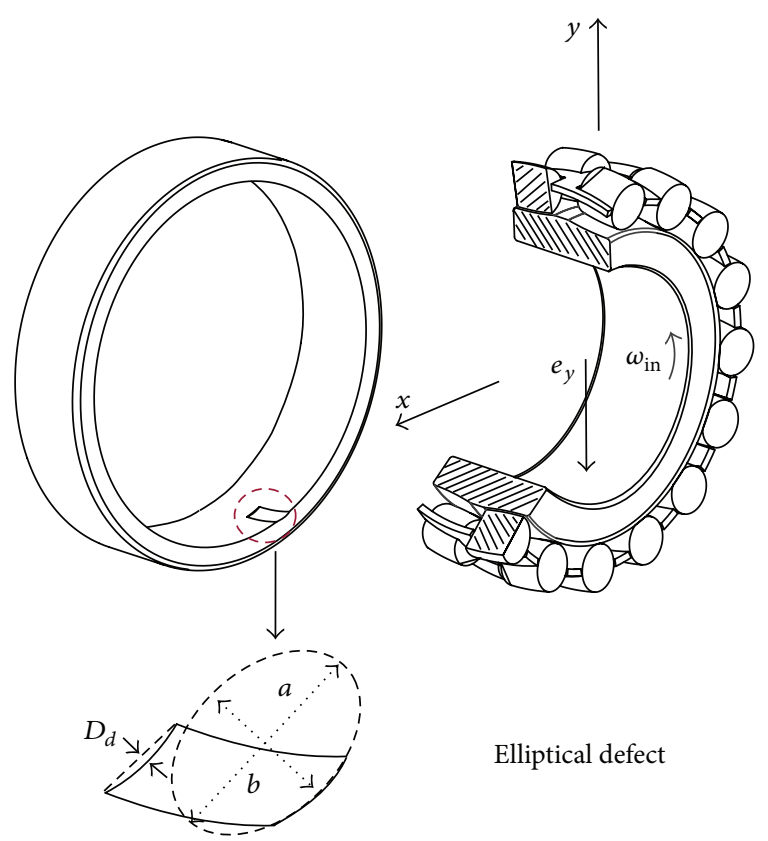

FIgURE 6: Properties of defect on outer ring.

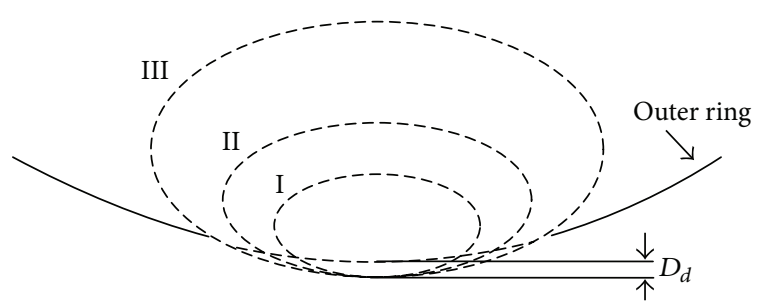

FIGURE 7: Outer ring: elliptical defect size.

With assumption of elliptical defect, connection loss between the roller and the rings does not happen immediately. So, in this case, size of the defect becomes important. Therefore, in the following example, effect of different elliptical defect size is considered. Figure 7 shows the three elliptical defects in outer ring of bearing. It is assumed that all these faults have the same depth, and the only difference is in their size. Table 2 lists the dimensions of the outer ring defects.

Figure 8 shows the system response for the three different size defects which are introduced in Figure 7. Frequency domain spectrum could detect the roller pass outer race frequency and second harmonic (Table 6). Furthermore, it is found that force amplitude is risen significantly by increasing the elliptical defect dimensions.

Figure 9 considers the effect of defect depth, where increasing the defect depth can rise the force amplitude. 


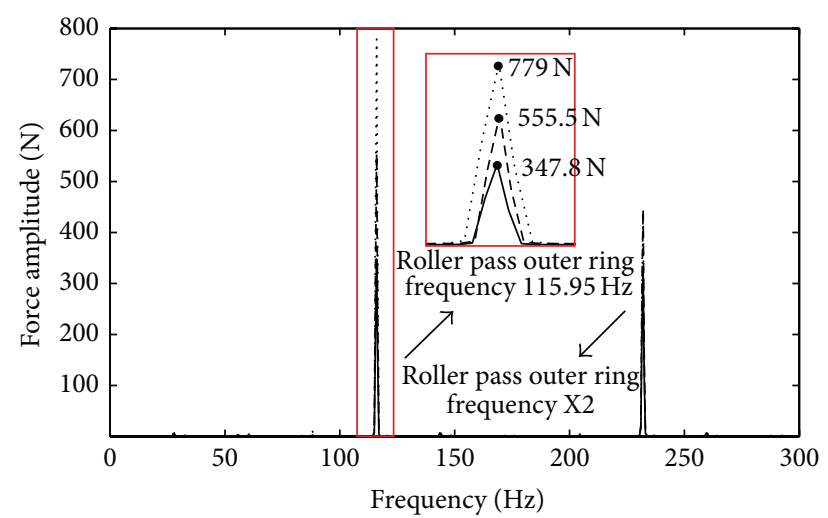

$\begin{array}{ll}\text { —- } & \text { Defect I } \\ \ldots-\text { Defect II } \\ \ldots \text {... } & \text { Defect III }\end{array}$

FIGURE 8: Defect size: force spectrum for defect on outer raceway in vertical direction.

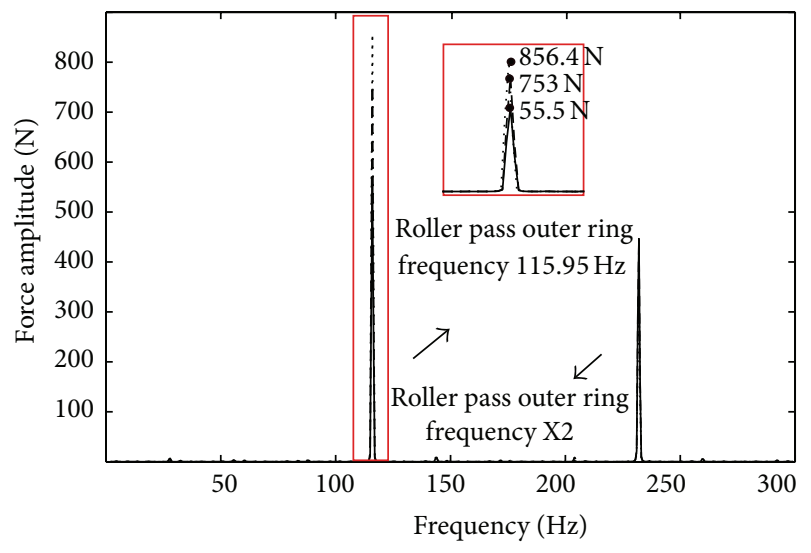

- Depth $0.05 \mathrm{~mm}$
--- Depth $0.10 \mathrm{~mm}$
… Depth $0.15 \mathrm{~mm}$

FIGURE 9: Defect depth: force spectrum for defect outer raceway in vertical direction.

Single elliptical defect ( $a=20 \mathrm{~mm}$ and $b=10 \mathrm{~mm}$ ) is chosen and maximum depth of the defect is increased from $0.05 \mathrm{~mm}$ to $0.15 \mathrm{~mm}$ and the defect is located in 280 degrees from the $x$ axis. Initial displacement for center of bearing in the vertical direction is assumed to be equal to $e_{y}=-0.0324 \mathrm{~mm}$ and inner race rotates with rate of $\omega_{\text {in }}=78.54 \mathrm{rad} / \mathrm{s}(750 \mathrm{rpm})$.

Force profile in time domain for elliptical defect is analyzed in Figure 10 for defect type II from Table 2 with depth $0.05 \mathrm{~mm}$. It is clearly shown that bearing force is decreased when roller enters defect area.

4.2. Load Analysis for Bearing with Inner Ring Defects. This section investigates the vibration response of defect on inner ring. The same as outer race case, initial displacement for center of bearing in the vertical direction is assumed to be equal to $e_{y}=-0.0324 \mathrm{~mm}$ and inner race rotates with a rate of $\omega_{\text {in }}=78.54 \mathrm{rad} / \mathrm{s}(750 \mathrm{rpm})$. Figure 11 shows the defect located on one side of the inner race.

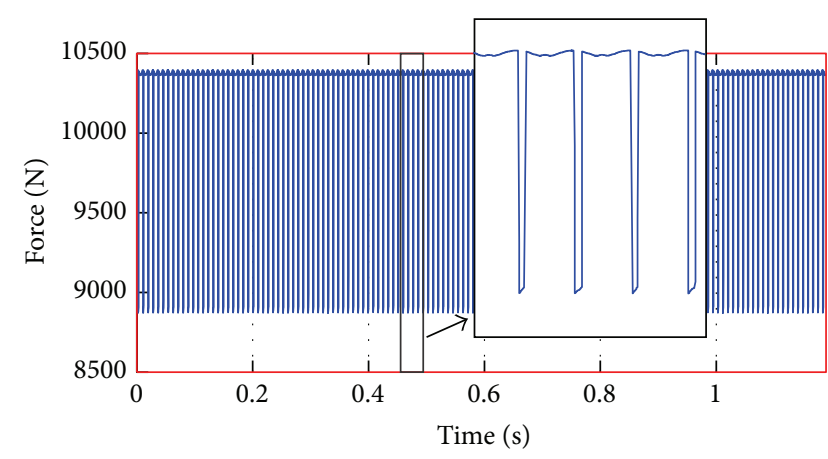

FIGURE 10: Bearing time domain force profile plot for outer race defect in vertical direction.

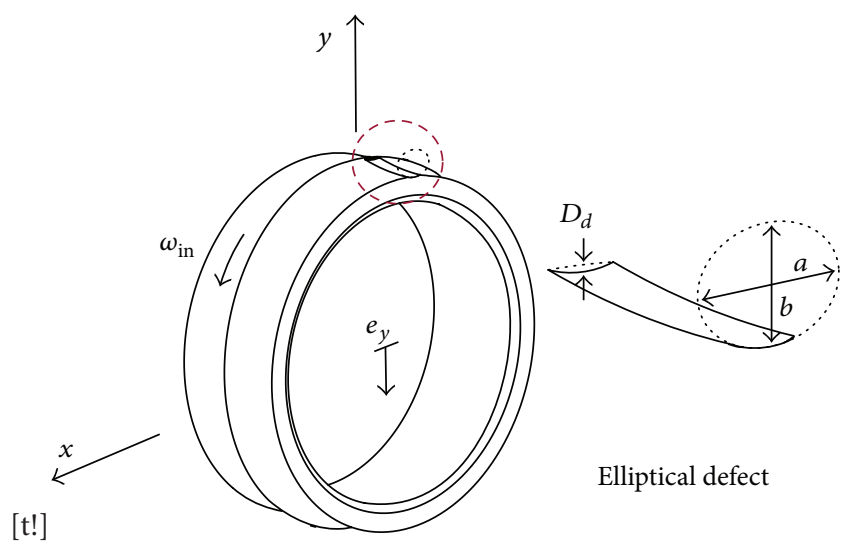

Figure 11: Properties of defect on inner ring.

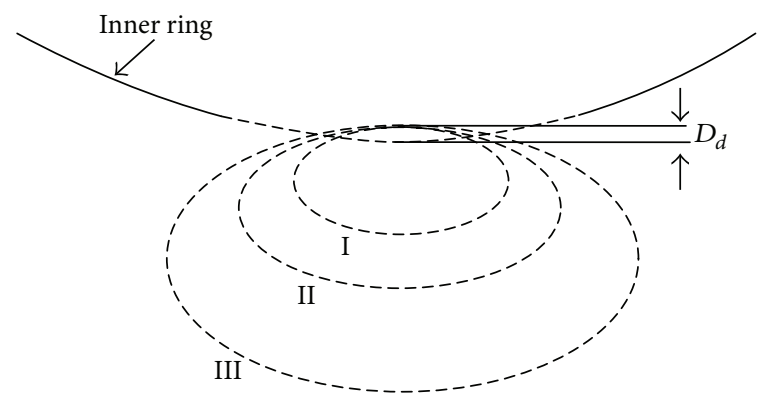

FIGURE 12: Inner ring: elliptical defect size.

Figure 12 shows the three elliptical defects in inner ring of bearing. It is assumed that all these faults have the same depth, and the only difference is in their size. Table 3 lists the parameters of the inner ring defect.

The roller pass inner ring frequency and its harmonics, with shaft rotating frequency harmonics (Table 6), can be detected in Figure 13. Compared to defect in outer ring, size of the elliptical defect does not have significant effect in force amplitude spectrum.

Figure 14 considers the effect of defect depth, where increasing the defect depth can rise the force amplitude. A single elliptical defect ( $a=20 \mathrm{~mm}$ and $b=10 \mathrm{~mm}$ ) is chosen, and maximum depth of the defect is increased from $0.05 \mathrm{~mm}$ 

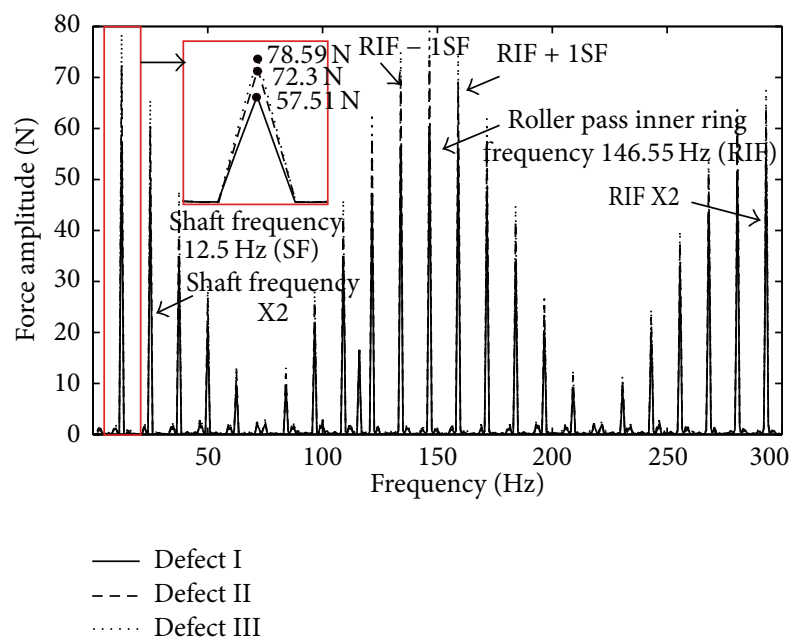

FIGURE 13: Defect size: force spectrum for defect on inner raceway in vertical direction.

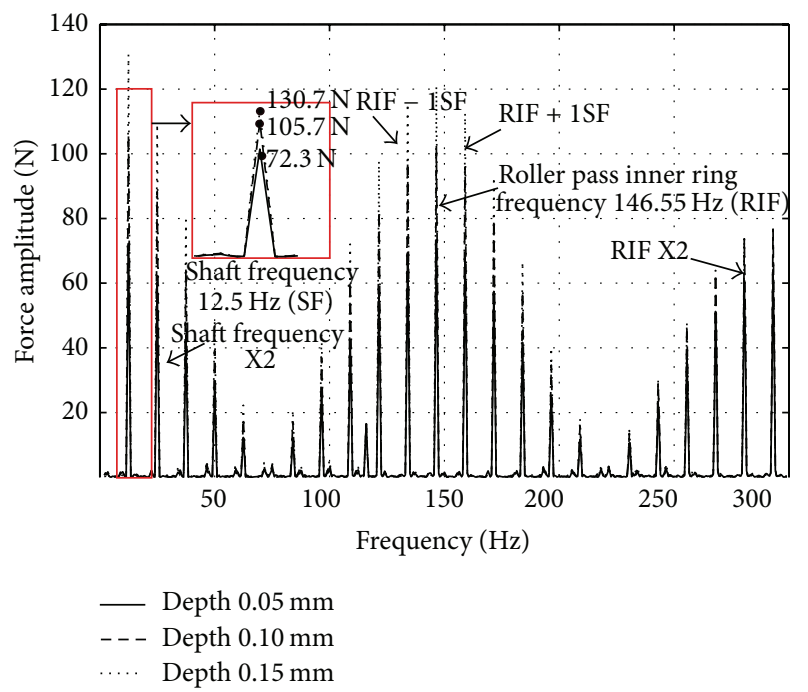

FIGURE 14: Defect depth: force spectrum for defect on inner raceway in vertical direction.

to $0.15 \mathrm{~mm}$ and the defect is located in $280^{\prime}$ from the $x$ axis. Initial displacement for center of bearing in the vertical direction is assumed to be equal to $e_{y}=-0.0324 \mathrm{~mm}$ and inner race rotates with rate of $\omega_{\text {in }}=78.54 \mathrm{rad} / \mathrm{s}(750 \mathrm{rpm})$.

Force profile in time domain for elliptical defect is analyzed in Figure 15 for defect type II from Table 3 with depth $0.05 \mathrm{~mm}$. It is clearly shown that bearing force drops down when roller enters defect area.

\section{Transient Analysis and Experimental Verification}

Rotor with two spherical roller bearings is a case study in full rotor-bearing system simulation and experimental verification. Figure 16 shows the schematic of the rotor and corresponding dimensions are listed in Table 4 .

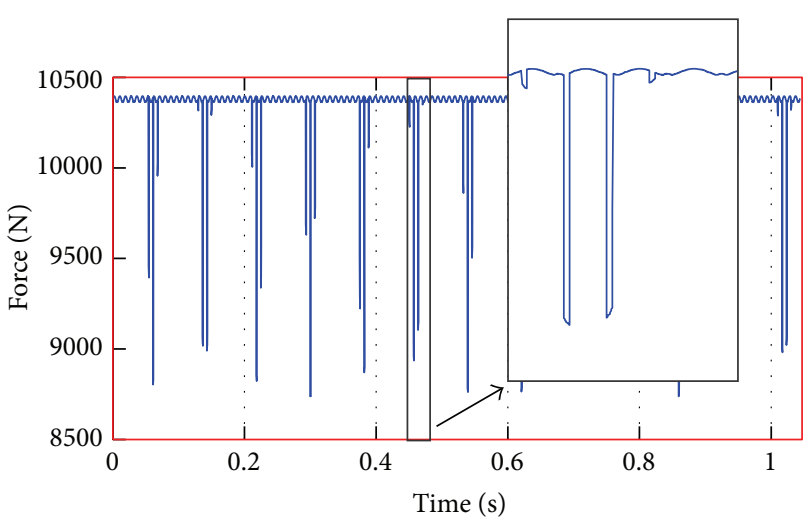

FIGURE 15: Bearing time domain force profile plot for inner race defect in vertical direction.

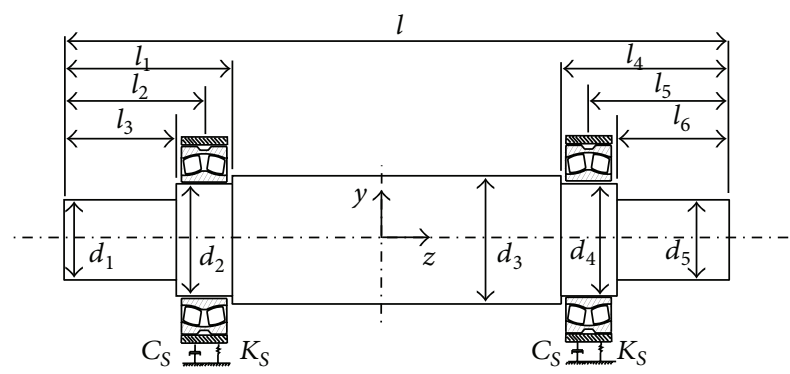

FIGURE 16: Rigid rotor with two spherical roller bearings [20].

TABLE 3: Inner ring defect parameters.

\begin{tabular}{lccc}
\hline Defect & Major axis $a$ & Minor axis $b$ & Defect width \\
\hline I & $10 \mathrm{~mm}$ & $5 \mathrm{~mm}$ & $1.20 \mathrm{~mm}$ \\
II & $20 \mathrm{~mm}$ & $10 \mathrm{~mm}$ & $2.01 \mathrm{~mm}$ \\
III & $30 \mathrm{~mm}$ & $15 \mathrm{~mm}$ & $3.64 \mathrm{~mm}$ \\
\hline
\end{tabular}

TABLE 4: Dimensions of the rotor-bearing system.

\begin{tabular}{lr}
\hline$d_{1}=70 \mathrm{~mm}$ & $l=600 \mathrm{~mm}$ \\
$d_{2}=d_{4}=80 \mathrm{~mm}$ & $l_{1}=l_{6}=100 \mathrm{~mm}$ \\
$d_{3}=88 \mathrm{~mm}$ & $l_{2}=l_{5}=130 \mathrm{~mm}$ \\
$d_{5}=70 \mathrm{~mm}$ & $l_{3}=l_{4}=160 \mathrm{~mm}$ \\
\hline
\end{tabular}

According to Newton's second law, the differential equation of motion for a rotating structure can be written as follows:

$$
\mathbf{M} \ddot{\mathbf{q}}(t)+(\mathbf{C}+\Omega \mathbf{G}) \dot{\mathbf{q}}(t)+\mathbf{K q}(t)=\mathbf{F}(t),
$$

where $\mathbf{M}, \mathbf{C}, \mathbf{G}$, and $\mathbf{K}$ are the mass, damping, gyroscopic, and stiffness matrices, respectively. $\mathbf{q}$ is the displacement in generalized coordinates, $\Omega$ is the shaft rotation speed, and $\mathbf{F}$ is a force vector that includes the external forces, the bearing forces, and the gravity forces for the rigid rotor. Firstly, governing differential equations would be decreased to a set of first-order differential equations, and then the state space form of the equation will be solved with MATLAB ODE integrators [20]. 
TABLE 5: Rotating structure properties.

\begin{tabular}{lccc}
\hline Mass & $m_{R}$ & 24.299 & $\mathrm{~kg}$ \\
Density & $\rho$ & 7850 & $\mathrm{~kg} / \mathrm{m}^{3}$ \\
Poisson's ratio & $v$ & 0.3 & - \\
Support mass & $m_{S}$ & 11 & $\mathrm{~kg}$ \\
Support stiffness & $K_{S}$ & $1 \cdot 10^{10}$ & $\mathrm{~N} / \mathrm{m}$ \\
Support damping & $C_{S}$ & $3 \cdot 10^{4}$ & $\mathrm{Ns} / \mathrm{m}$ \\
\hline
\end{tabular}

TABLE 6: Characteristic frequencies of SRB.

\begin{tabular}{lcc}
\hline Rotation speed $(\mathrm{rpm})$ & 763 & 750 \\
Shaft frequency $(\mathrm{Hz})$ & 12.72 & 12.5 \\
Cage frequency $(\mathrm{Hz})$ & 5.61 & 5.52 \\
Roller pass outer ring frequency $(\mathrm{Hz})$ & 117.96 & 115.95 \\
Roller pass inner ring frequency $(\mathrm{Hz})$ & 149.08 & 146.54 \\
\hline
\end{tabular}

The beam element is used to model the rotor and finite element method is applied. Each element has four degrees of freedom per node. By defining 17 nodes in the length of the rotor, this rotor-bearing system has 72 dofs where 4 dofs come from bearings supports lateral displacements, and the remaining 68 dofs describe the rotor displacements. A linear spring-damper is defined for connection of bearing housing to the ground. Rotating structure properties are shown in Table 5. In this system, it is assumed that support structure has higher stiffness compared with bearing stiffness, and support damping is rough estimation value which is calculated by defining $5 \%$ as modal damping ratio.

Figure 17 shows the measurement setup where the bearing with defect is placed in one side of the rotor. Measurements were done for inner and outer ring defect separately. Defect parameters are shown in Tables 2 and 3 for defect type III. External belt drive rotates the rotor and data acquisition starts to record the data when the system settles down in constant rotational velocity. $500 \pm 10 \mathrm{~N}$ external force is applied to the rotor in the vertical direction to clarify the vibration originating from bearing defect. External force was measured by washer load cell (HC 2001, DS Europe). Furthermore, two ICP accelerometers $(98 \mathrm{mV} / \mathrm{g})$ are used to measure the vibrations, which are located on top of the bearing housing transferring data to acquisition unit (CSI 2130). 4096 samples are recorded in 4 seconds at $1024 \mathrm{~Hz}$.

For the outer race defect, Figure 18 shows spectrum for vertical displacement amplitude in frequency domain and compares the simulation result with measurements. Fast Fourier Transform (FFT) analysis is applied to transient analysis results to detect high peaks in frequency domain (sampled at $1024 \mathrm{~Hz}$ for 4 seconds). Simulation spectrum shows peaks correctly on the roller pass outer ring frequency $(118.1 \mathrm{~Hz})$ and its second harmonic spectra (displayed in Table 6). Similar frequencies can also be detected in measurement at $115.1 \mathrm{~Hz}$. This frequency gap might originate from internal slipping between bearing components [20]. Another important point is that actual rotor-bearing systems are suffering from unknown noises which can be visible in measured signals (Figure 18(b)). Analytical model has not the capability to detect all unknown vibration noises.

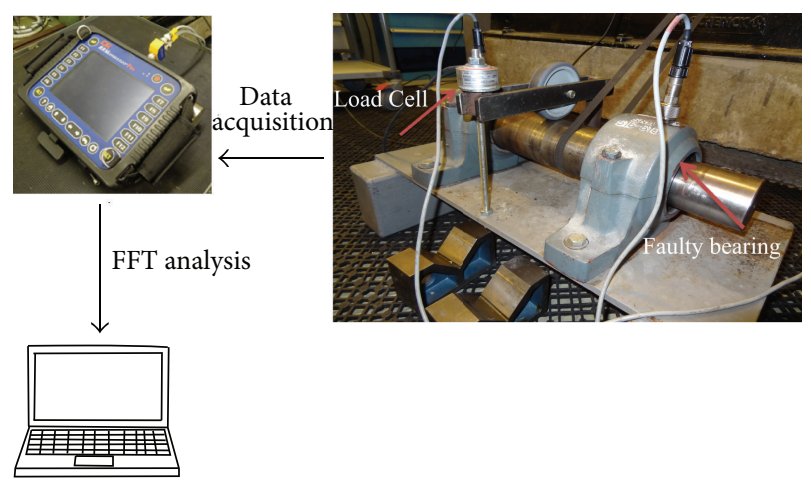

FIGURE 17: Test setup for bearing defect experiments [20].

For the inner race defect, Figure 19 shows spectrum for vertical displacement amplitude in frequency domain and compares the simulation result with measurements.

Spectrum contains peaks at rotor rotation velocity and its harmonics in simulation and measurement plots. Roller pass inner ring frequency (RIF) and its harmonics (RIFSF) are also visible in plots.

\section{Conclusion}

Vibration simulation of spherical roller bearing with local defect on inner and outer raceways was introduced and simulation predictions were compared and verified with measurement data. Rotor is modeled using finite element method, and governing equations of motion were solved by MATLAB numerical integrators. An important achievement was efficiency of the proposed bearing model, which is demonstrated by different numerical examples and can be used in actual rotor-bearing simulations. Bearing force was calculated from summation of roller contact forces using Hertzian contact theory which is the source of nonlinearity in the system. With assumption of elliptical surface concavity on inner and outer raceways, roller's connection with rings is not lost immediately and it prevents impulse force (available literatures) when roller passes over the defect district. It means that the roller is in contact with surfaces, whenever the defect depth is smaller than elastic deformation between rollers and races plus also bearing internal clearance. As a result, this roller contact force should be considered in total bearing force. Furthermore, because of changing the radii of curvature in defect region, new contact stiffness needs to be defined. Numerical examples demonstrated a set of dynamic responses according to defect dimension, type, and position. Hence, it is possible to classify an SRB defect by comparing the measured data. Numerical results also exposed that local defect would be detected in bearing characteristics frequencies. The measurements detected bearing characteristic frequencies different than those that simulation predicted once. This frequency difference between two approaches is found to be $1.7-2.7 \%$. This is originated from internal slipping between bearing internal components which are ignored in early assumptions. Nevertheless, the actual rotor-bearing system has unknown parameters which cannot be predefined in simulation process. 


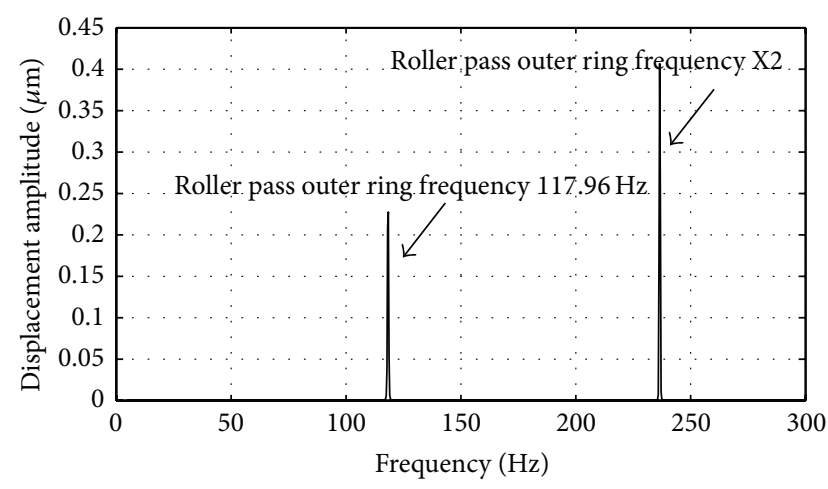

(a)

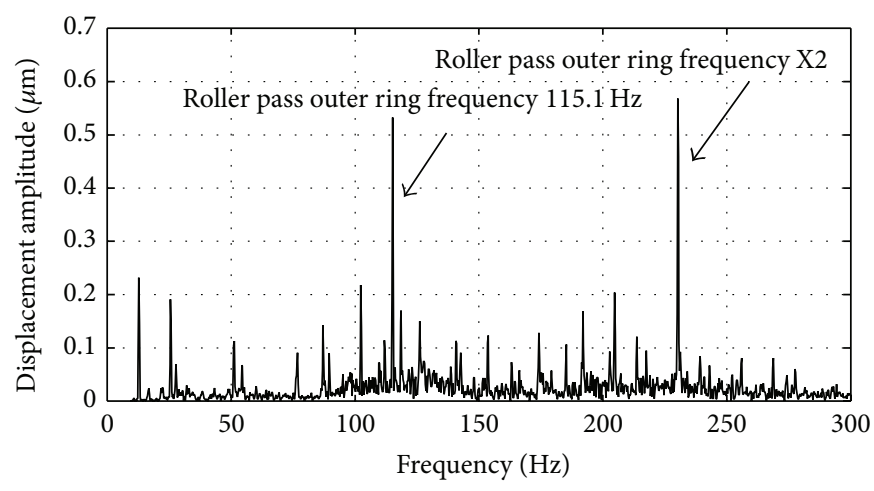

(b)

FIGURE 18: Vertical displacement amplitude for outer ring defect: (a) simulation; (b) measurement data.

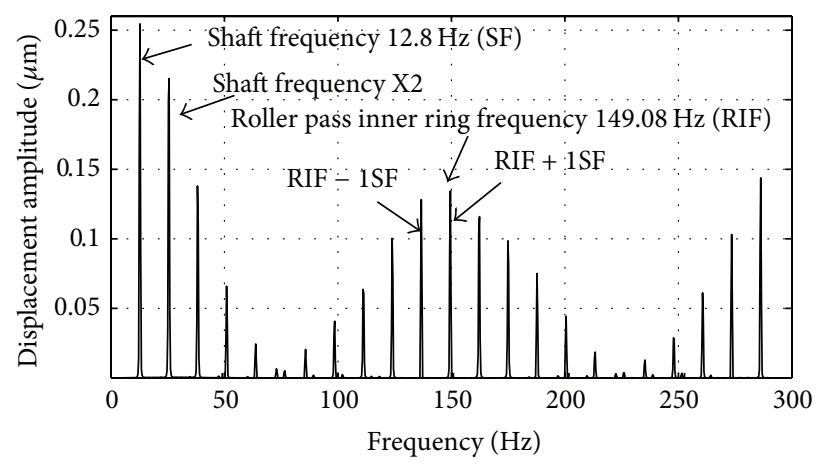

(a)

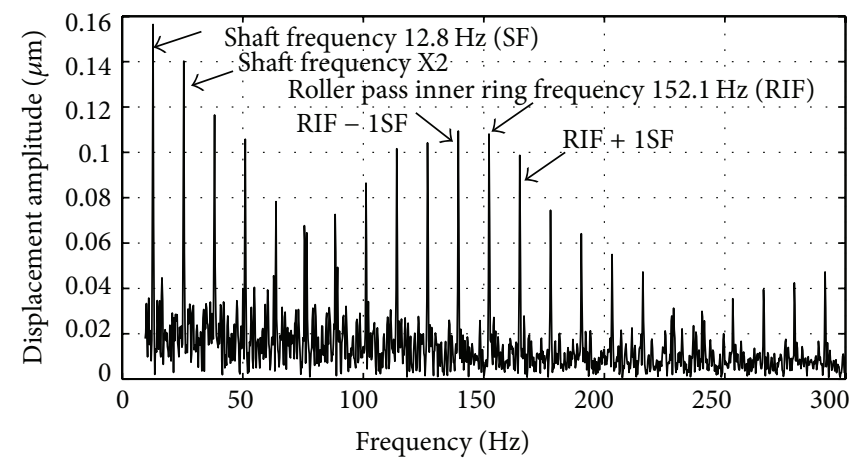

(b)

FIGURE 19: Vertical displacement amplitude for inner ring defect: (a) simulation; (b) measurement data.

\section{Appendices}

\section{A. Calculation of Roller Additional Displacement in Defect Region}

Based on geometric parameters of elliptical defect which is shown in Figure 20, the following parametric equations can be written:

$$
\begin{aligned}
\overline{P F}_{1}+\overline{P F}_{2} & =2 a \\
\overline{P F}_{1}^{2} & =\overline{O P}^{2}+\overline{O F}_{1}^{2}-2 \overline{O P} \cdot \overline{O F}_{1} \cdot \cos \psi_{1} \\
\overline{P F}_{2}^{2} & =\overline{O P}^{2}+\overline{O F}_{2}^{2}-2 \overline{O P} \cdot \overline{O F}_{2} \cdot \cos \psi_{2} .
\end{aligned}
$$

Finally, $\overline{O P}$ can be calculated to get defect depth depending on roller angular position.

\section{B. Characteristic Frequencies of Bearing}

Cage rotational frequency can be calculated by

$$
f_{\mathrm{cg}}=\frac{f_{R}}{2}\left(1+\frac{d_{r}}{d_{p}} \cos \phi_{0}\right)
$$

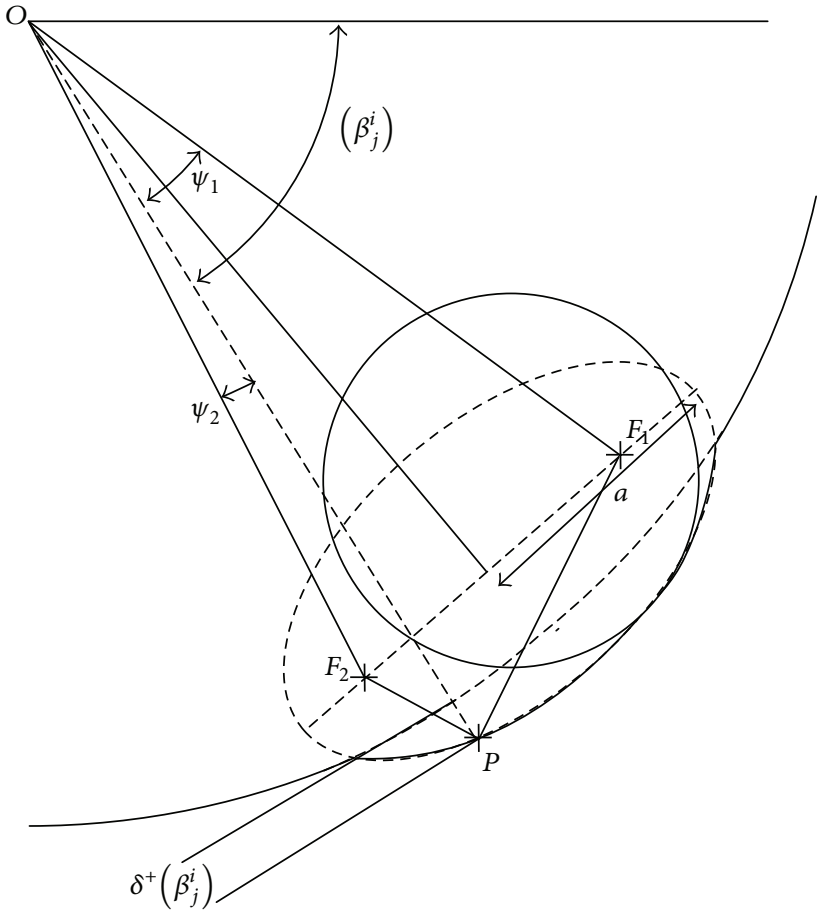

Figure 20: Defect depth calculation. 
and roller pass outer ring frequency can be calculated by

$$
f_{\text {rpof }}=N \frac{f_{R}}{2}\left(1-\frac{d_{r}}{d_{p}} \cos \phi_{0}\right)
$$

and also roller pass inner ring frequency can be calculated by

$$
f_{\text {rpif }}=N \frac{f_{R}}{2}\left(1+\frac{d_{r}}{d_{p}} \cos \phi_{0}\right),
$$

where $f_{R}$ is the shaft frequency and $d_{p}$ is a bearing pitch diameter which is defined as

$$
d_{p}=R_{\text {out }}+R_{\text {in }}
$$

\section{Conflict of Interests}

The authors declare that there is no conflict of interests regarding the publication of this paper.

\section{References}

[1] N. Tandon and A. Choudhury, "An analytical model for the prediction of the vibration response of rolling element bearings due to a localized defect," Journal of Sound and Vibration, vol. 205, no. 3, pp. 275-292, 1997.

[2] C. S. Sunnersjo, "Rolling bearing vibrations-the effects of geometrical imperfections and wear," Journal of Sound and Vibration, vol. 98, no. 4, pp. 455-474, 1985.

[3] P. D. McFadden and J. D. Smith, "Model for the vibration produced by a single point defect in a rolling element bearing," Journal of Sound and Vibration, vol. 96, no. 1, pp. 69-82, 1984.

[4] P. D. McFadden and J. D. Smith, "The vibration produced by multiple point defects in a rolling element bearing," Journal of Sound and Vibration, vol. 98, no. 2, pp. 263-273, 1985.

[5] M. Nakhaeinejad and M. D. Bryant, "Dynamic modeling of rolling element bearings with surface contact defects using bond graphs," Journal of Tribology, vol. 133, no. 1, Article ID 011102, 2011.

[6] F. Wang, M. Jing, J. Yi, G. Dong, H. Liu, and B. Ji, "Dynamic modelling for vibration analysis of a cylindrical roller bearing due to localized defects on raceways," Proceedings of the Institution of Mechanical Engineers, Part K: Journal of Multi-Body Dynamics, vol. 229, no. 1, pp. 39-64, 2015.

[7] J. Sopanen and A. Mikkola, "Dynamic model of a deep-groove ball bearing including localized and distributed defects. Part 1. Theory," Proceedings of the Institution of Mechanical Engineers Part K-Journal of Multi-Body Dynamics, vol. 217, no. 3, pp. 201211, 2003.

[8] J. Sopanen and A. Mikkola, "Dynamic model of a deep-groove ball bearing including localized and distributed defects. Part 2: implementation and results," Proceedings of the Institution of Mechanical Engineers Part K: Journal of Multi-body Dynamics, vol. 217, no. 3, pp. 213-223, 2003.

[9] Z. Kiral and H. Karagülle, "Vibration analysis of rolling element bearings with various defects under the action of an unbalanced force," Mechanical Systems and Signal Processing, vol. 20, no. 8, pp. 1967-1991, 2006.

[10] A. Rafsanjani, S. Abbasion, A. Farshidianfar, and H. Moeenfard, "Nonlinear dynamic modeling of surface defects in rolling element bearing systems," Journal of Sound and Vibration, vol. 319, no. 3-5, pp. 1150-1174, 2009.
[11] P. K. Kankar, S. C. Sharma, and S. P. Harsha, "Fault diagnosis of high speed rolling element bearings due to localized defects using response surface method," Journal of Dynamic Systems, Measurement and Control-Transactions of the ASME, vol. 133, no. 3, Article ID 031007, 2011.

[12] M. Tadina and M. Boltežar, "Improved model of a ball bearing for the simulation of vibration signals due to faults during runup," Journal of Sound and Vibration, vol. 330, no. 17, pp. 42874301, 2011.

[13] J. Liu, Y. M. Shao, and T. C. Lim, "Vibration analysis of ball bearings with a localized defect applying piecewise response function," Mechanism and Machine Theory, vol. 56, pp. 156-169, 2012.

[14] P. K. Kankar, S. C. Sharma, and S. P. Harsha, "Vibration based performance prediction of ball bearings caused by localized defects," Nonlinear Dynamics, vol. 69, no. 3, pp. 847-875, 2012.

[15] M. Behzad, A. R. Bastami, and D. Mba, "A new model for estimating vibrations generated in the defective rolling element bearings," Journal of Vibration and Acoustics, vol. 133, no. 4, Article ID 041011, 2011.

[16] N. Sawalhi and R. B. Randall, "Simulating gear and bearing interactions in the presence of faults: part I. The combined gear bearing dynamic model and the simulation of localised bearing faults," Mechanical Systems and Signal Processing, vol. 22, no. 8, pp. 1924-1951, 2008.

[17] N. Sawalhi and R. B. Randall, "Simulating gear and bearing interactions in the presence of faults. Part II. Simulation of the vibrations produced by extended bearing faults," Mechanical Systems and Signal Processing, vol. 22, no. 8, pp. 1952-1966, 2008.

[18] N. Sawalhi and R. B. Randall, "Vibration response of spalled rolling element bearings: observations, simulations and signal processing techniques to track the spall size," Mechanical Systems and Signal Processing, vol. 25, no. 3, pp. 846-870, 2011.

[19] L. Niu, H. Cao, Z. He, and Y. Li, "Dynamic modeling and vibration response simulation for high speed rolling ball bearings with localized surface defects in raceways," Journal of Manufacturing Science and Engineering-Transactions of the ASME, vol. 136, no. 4, Article ID 041015, 2014.

[20] B. Ghalamchi, Dynamic Analysis Model of Spherical Roller Bearings with Defects, Lappeenranta University of Technology, 2014.

[21] A. Moazenahmadi, D. Petersen, C. Howard, and N. Sawalhi, "Defect size estimation and analysis of the path of rolling elements in defective bearings with respect to the operational speed," in INTER-NOISE and NOISE-CON Congress and Conference Proceedings, vol. 249, pp. 4242-4251, Institute of Noise Control Engineering, 2014.

[22] D. Petersen and C. Howard, "Bearing defect size estimation for extended raceway defects," INTER-NOISE and NOISE-CON Congress and Conference Proceedings, vol. 249, no. 5, pp. 27872796, 2014.

[23] Z.-M. Li, Q. Zhou, Q. An, and Z.-D. Wang, "Dynamic analysis of an unbalanced rotor-water pump-bearing system considering varying compliance effect and localized defects on bearing races," Proceedings of the Institution of Mechanical Engineers, Part K, 2015.

[24] J. Liu, Y. Shao, and W. D. Zhu, "A new model for the relationship between vibration characteristics caused by the time-varying contact stiffness of a deep groove ball bearing and defect sizes," Journal of Tribology, vol. 137, no. 3, Article ID 031101, 2015.

[25] N. Tandon and A. Choudhury, "Review of vibration and acoustic measurement methods for the detection of defects in 
rolling element bearings," Tribology International, vol. 32, no. 8, pp. 469-480, 1999.

[26] J. B. Yu, "Local and nonlocal preserving projection for bearing defect classification and performance assessment," IEEE Transactions on Industrial Electronics, vol. 59, no. 5, pp. 2363-2376, 2012.

[27] F. Bolaers, O. Cousinard, P. Estocq, X. Chiementin, and J.P. Dron, "Comparison of denoising methods for the early detection of fatigue bearing defects by vibratory analysis," JVC/Journal of Vibration and Control, vol. 17, no. 13, pp. 19831993, 2011.

[28] B. Kilundu, X. Chiementin, and P. Dehombreux, "Singular spectrum analysis for bearing defect detection," Journal of Vibration and Acoustics, vol. 133, no. 5, Article ID 051007, 2011.

[29] V. N. Patel, N. Tandon, and R. K. Pandey, "Defect detection in deep groove ball bearing in presence of external vibration using envelope analysis and Duffing oscillator," Measurement, vol. 45, no. 5, pp. 960-970, 2012.

[30] C. Li and M. Liang, "Continuous-scale mathematical morphology-based optimal scale band demodulation of impulsive feature for bearing defect diagnosis," Journal of Sound and Vibration, vol. 331, no. 26, pp. 5864-5879, 2012.

[31] L. Xiang and A. J. Hu, "New feature extraction method for the detection of defects in rolling element bearings," Journal of Engineering for Gas Turbines and Power, vol. 134, no. 8, Article ID 84501, 5 pages, 2012.

[32] H. Shen, S. X. Li, D. Y. Gu, and H. X. Chang, "Bearing defect inspection based on machine vision," Measurement: Journal of the International Measurement Confederation, vol. 45, no. 4, pp. 719-733, 2012.

[33] M. Cao and J. Xiao, "A comprehensive dynamic model of double-row spherical roller bearing-model development and case studies on surface defects, preloads, and radial clearance," Mechanical Systems and Signal Processing, vol. 22, no. 2, pp. 467489, 2008.

[34] F. Ma, P. Ji, Z. Li, B. Wu, and Q. An, "Influences of off-sized rollers on mechanical performance of spherical roller bearings," Proceedings of the Institution of Mechanical Engineers Part K: Journal of Multi-Body Dynamics, 2015.

[35] B. Ghalamchi, J. Sopanen, and A. Mikkola, "Simple and versatile dynamic model of spherical roller bearing," International Journal of Rotating Machinery, vol. 2013, Article ID 567542, 13 pages, 2013.

[36] R. J. Kleckner and J. Pirvics, "Spherical roller bearing analysis," Journal of Lubrication Technology, vol. 104, no. 1, pp. 99-108, 1982. 


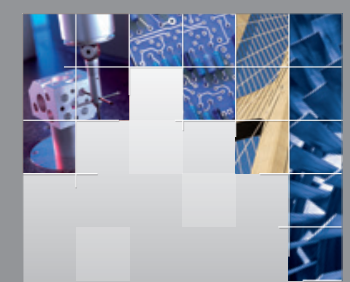

\section{Enfincering}
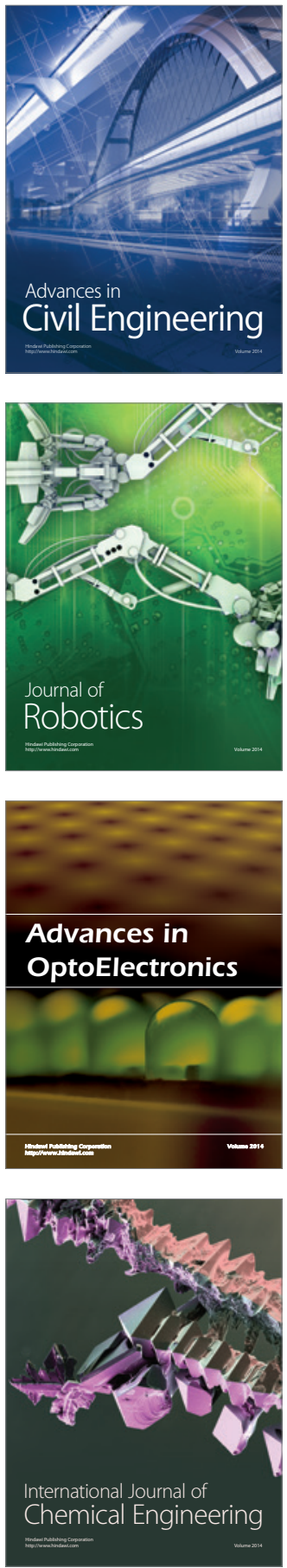

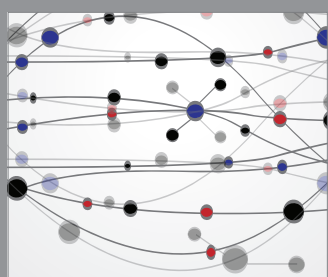

The Scientific World Journal

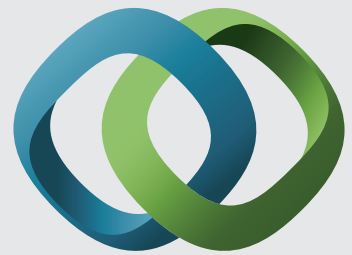

\section{Hindawi}

Submit your manuscripts at

http://www.hindawi.com
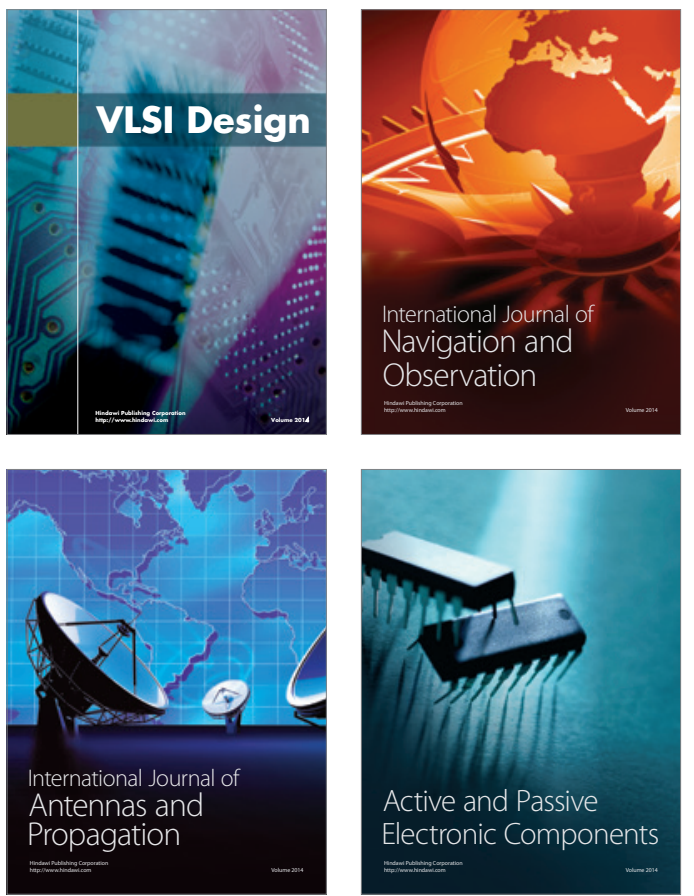
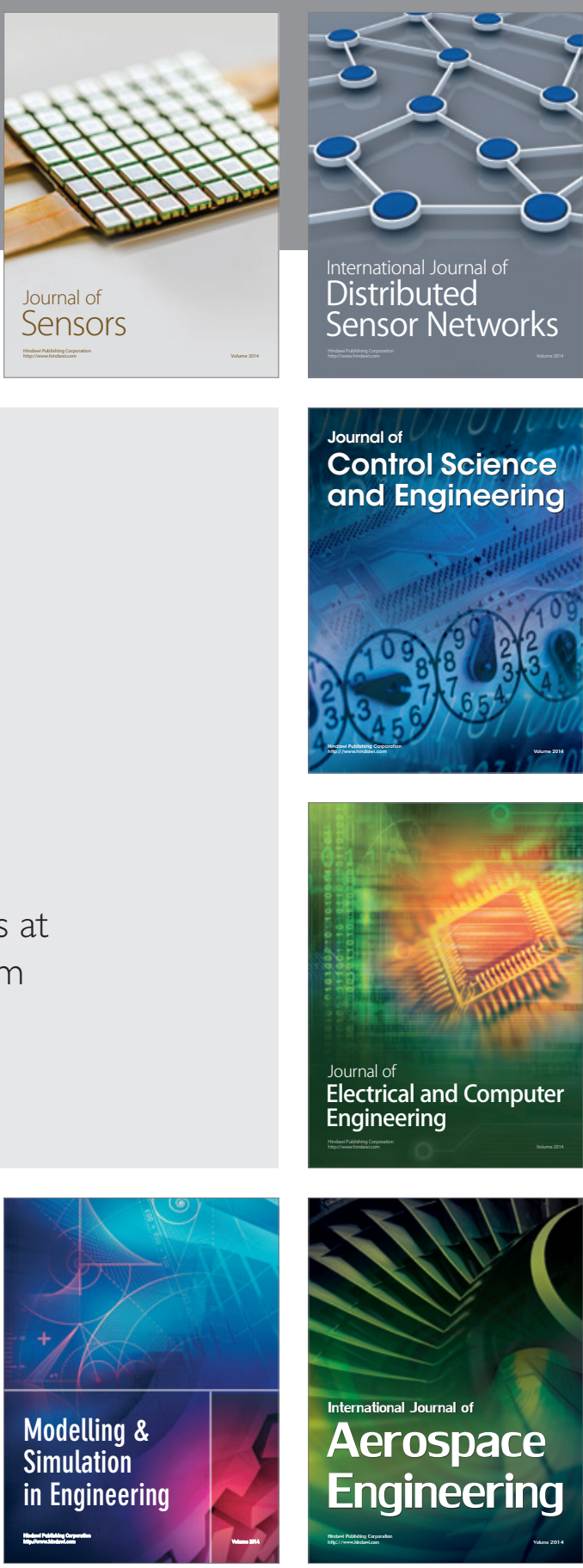

International Journal of

Distributed

Sensor Networks

Journal of

Control Science

and Engineering
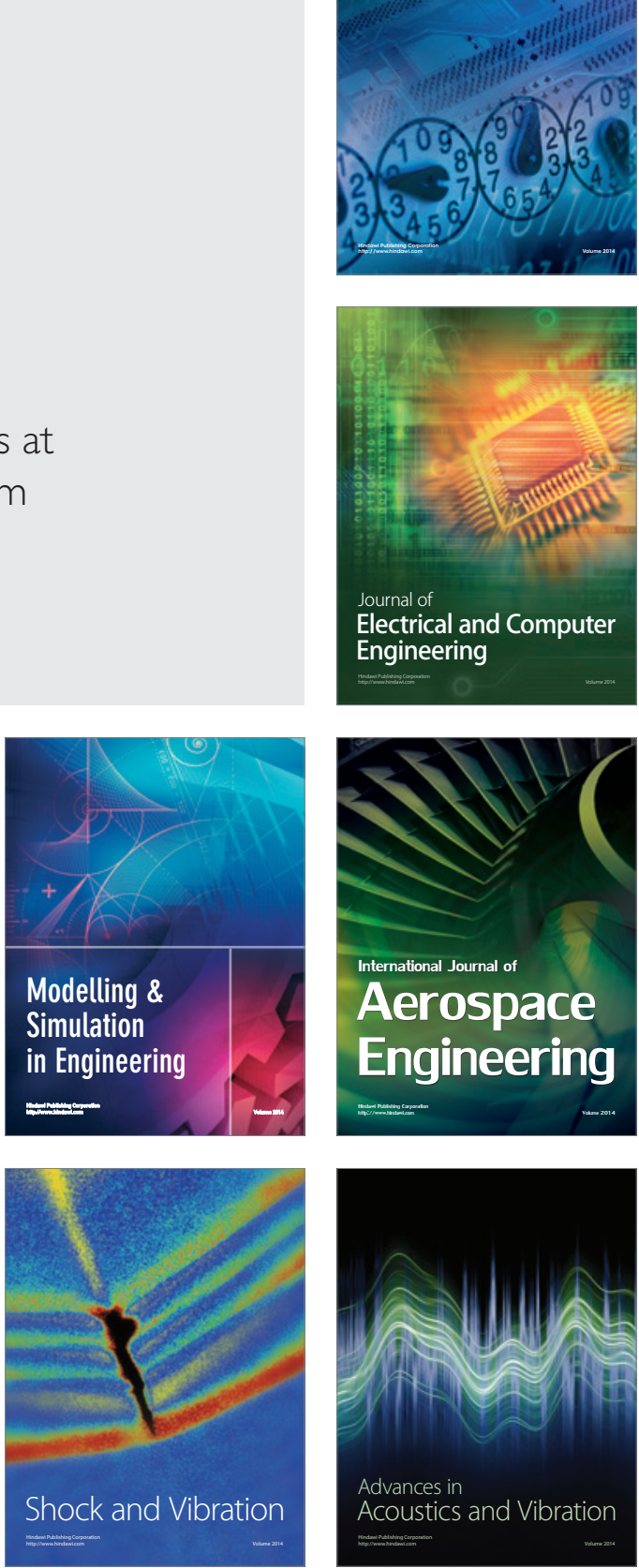